\title{
Value in Hepatitis C Virus Treatment: A Patient-Centered Cost-Effectiveness Analysis
}

\author{
T. Joseph Mattingly II ${ }^{1}$ - Julia F. Slejko ${ }^{2}$ (D) Eberechukwu Onukwugha ${ }^{2}\left(\right.$ Eleanor M. Perfetto $^{2,3}$ (E) \\ Shyamasundaran Kottilil ${ }^{4} \oplus$. C. Daniel Mullins ${ }^{2}[0$
}

Published online: 2 December 2019

(c) The Author(s) 2019

\begin{abstract}
Background Innovations in hepatitis C virus (HCV) therapy included in traditional comparative evaluations focus on sustained virologic response (SVR) without addressing challenges patients report beyond virologic cure. This study aims to evaluate the cost-effectiveness of HCV drug therapy with a patient-centered approach.

Methods An individual-based Markov model was constructed using guidance from a stakeholder advisory board (SAB), a patient Delphi panel, and published literature to evaluate direct-acting antivirals (DAAs) compared to no treatment. The United States (US) health sector and societal perspectives were considered for 10- and 20-year time horizons. Inputs for treatment costs and effectiveness reflect a generic regimen. Indirect costs used for the societal model included estimates from self-reported productivity in a matched-control sample. Beyond the traditional quality-adjusted life-year (QALY) health outcome, this study included two novel measures developed from the Delphi panel and SAB: infected life-years and workdays missed. All costs were measured in 2018 US dollars.

Results Health sector costs and QALYs were higher in the treatment group in both 10- and 20-year models. Total infected life-years and workdays missed were reduced in the treatment group for both models. When costs of absenteeism, presenteeism, and patient/ caregiver time were included, the DAA intervention was cost-saving at both 10 and 20 years. Health sector results were sensitive to drug costs and utility estimates for post-SVR health states. Societal results were sensitive to presenteeism estimates and drug costs. Conclusion Treatment was cost-effective from a health sector perspective and cost-saving when including non-health costs such as patient/caregiver time and productivity.
\end{abstract}

\section{Introduction}

\subsection{A Patient-Centered Legislative Dilemma}

Electronic supplementary material The online version of this article (https://doi.org/10.1007/s40273-019-00864-8) contains supplementary material, which is available to authorized users.

\section{T. Joseph Mattingly II}

jmattingly@rx.umaryland.edu

1 Department of Pharmacy Practice and Science, University of Maryland School of Pharmacy, 20 North Pine Street, N415, Baltimore, MD 21201, USA

2 Department of Pharmaceutical Health Services Research, University of Maryland School of Pharmacy, Baltimore, MD, USA

3 National Health Council, Washington, DC, USA

4 Institute of Human Virology, University of Maryland School of Medicine, Baltimore, MD, USA
In the United States (US), the Patient-Centered Outcomes Research Institute (PCORI) supports patient-centered comparative effectiveness research (CER) along with other patient-centered research [1]. Created with the passage of the Patient Protection and Affordable Care Act in 2010, this relatively new institute has allocated over $\$ 2$ billion in research projects to fulfill its mission of producing and promoting evidence-based information that comes from research guided by patients [2]. However, the Affordable Care Act specifically limited PCORI when supporting cost-effectiveness research that uses a quality-adjusted life-year (QALY) to limit access to treatment through the following language in the statute:

"The Patient-Centered Outcomes Research Institute established under section 1181(b)(1) shall not 


\section{Key Points for Decision Makers}

When considering societal perspective costs, including patient/caregiver time and productivity losses through patient absenteeism and presenteeism, direct-acting antivirals were actually cost-saving in both 10 - and 20 -year scenarios.

Treatment leads to a reduction in years living with the virus and the number of workdays missed.

develop or employ a dollars-per-quality adjusted life year (or similar measure that discounts the value of a life because of an individual's disability) as a threshold to establish what type of health care is cost effective or recommended" [3].

Leading cost-effectiveness experts have consistently recommended all cost-effectiveness analyses (CEAs) report an incremental cost-effectiveness ratio (ICER), calculated as the difference in costs in the numerator and the difference in effectiveness (measured in QALYs) in the denominator. However, interpretation of the statute has essentially banned PCORI from funding CEAs, because of the use of the QALY [4-6]. For health economists, when a leading funder of patient-centered outcomes research decided not to support CEAs, it limited where their study proposals could be submitted. While PCORI became a catalyst for new CER, an unintended consequence of the QALY prohibition was the establishment of a solid line of demarcation between patient-centricity and CEA.

\subsection{Cost Effectiveness in Hepatitis C and the Potential for Patient Engagement}

The cost effectiveness of medications used to treat chronic hepatitis $\mathrm{C}$ virus (HCV) patients in the US has been studied extensively with a variety of clinical, economic model, and real-world data investigations [7, 8]. Effectiveness outcomes in economic models for HCV treatments have traditionally focused on survival, reducing all-cause and liver-related mortality, and morbidity through healthrelated quality-of-life (HRQoL) assessments, leading to utility adjustments for estimating QALYs gained [8]. The Institute for Clinical and Economic Review, an organization in the US that conducts value assessments, evaluated direct-acting antivirals (DAAs) in 2015 in a way that mirrored other traditional CEAs in HCV, with a cost-perQALY result with no patient input [9]. Outside of the US, the German Institute for Quality and Efficiency in Health Care (IQWiG) developed a value assessment of
HCV treatment options informed by patient preferences, leading to a proposed "efficiency frontier" to inform pricing without reporting a cost per QALY $[10,11]$. The IQWiG model identified eight clinical attributes and used discrete choice experiments for weighting them in a final model [11]. While the IQWiG pilot demonstrated a novel approach to CEA without the QALY, it did not appear that the researchers systematically engaged HCV patients throughout the process or partnered with patients to improve study methodology or dissemination of results $[12,13]$. Though nothing restricts health economists from incorporating the voice of $\mathrm{HCV}$ patients throughout their work, the number of $\mathrm{HCV}$-specific CEAs that reflect value from the patient's perspective has been limited [14]. Here, we report the results of an economic model for HCV treatments guided by a patient-centered advisory board and informed by a patient-only Delphi panel to capture model variables and outcomes important to patients [15].

\section{Methods}

\subsection{Patient-Centered Model Overview}

The Value in Hepatitis C Virus Treatment Patient-Centered Model was developed by following the 10-Step Framework for Continuous Patient Engagement [12]. An 11-member, patient-centered, stakeholder advisory board (SAB) including four HCV patients, three infectious disease specialists, one general practitioner, two pharmacists, and a national patient advocacy organization representative was formed [15]. Health economists typically solicit clinical experts. This project incorporated input from five patient experts throughout the study. The SAB reviewed components of the model, including structure, inputs, outcomes, and the presentation of results. In-person meetings and conference calls were scheduled throughout the project for iterative feedback and general qualitative discussion. Formal voting was not requested if there was general consensus on a topic. The SAB helped inform the methods of the Delphi process, previously published, and the following economic model [15].

\subsection{Microsimulation Model}

An individual-level Markov model was used to simulate the natural history and progression of liver disease among individuals infected with chronic $\mathrm{HCV}$ and compare outcomes of recommended treatment strategies similar to previously published research [16-19]. The target population reflected the age and disease severity of patients diagnosed with HCV who were likely to be treated in the outpatient setting with a medication regimen [20-22]. The cycle length for each period was 1 year, for a total of 10 and 20 cycles, with an 
annual discount rate of 3\% used for all costs and effects [23]. The 10- and 20-year time horizons were both reported to demonstrate the impact of time on model outcomes. A generic treatment strategy using a DAA regimen was based on clinical guidelines developed by the American Association for the Study of Liver Diseases (AASLD) in partnership with the Infectious Diseases Society of America (IDSA) and the patient-only Delphi panel [24].

\subsection{Disease Progression Probability}

Progression of disease was scored using advancing fibrosis stages categorized by METAVIR [25]. Health states representing the natural history of liver disease associated with chronic HCV infection and progression probabilities of transitioning among disease stages from previous studies were utilized [18, 26-28]. Patients entered the model at different fibrosis stages based on estimates representative of the US population used in previous studies [18]. Probability of DAA treatment success was estimated at 90\% (82-98\%) based on published systematic reviews [29, 30]. Patients reaching sustained virologic response (SVR) after treatment entered post-SVR health states with reduced progression rates estimated from histologic benefits previously reported $[18,31]$. Patients who failed to reach SVR entered a natural progression process with baseline fibrosis staging severity ranging between METAVIR F0 and F4 [28]. Patients in the F0 state who failed to reach SVR or were untreated were able to spontaneously achieve SVR and enter the postSVR health states [16]. From the post-SVR state, reinfection resulted in a set of advanced progression states, with fibrosis progression estimated at twice the natural history progression, with no opportunity for retreatment [27, 32, 33]. Risk of reinfection was applied equally to all post-SVR states [34].

\subsection{Costs}

The costs evaluated in this study included both US health system and societal perspectives as shown in the impact inventory (Table 1). Drug costs in the first year of therapy for DAAs were estimated based off of the VA Federal Supply Schedule (VAFSS) listed for each treatment regimen for the duration of therapy for the base case [35]. Annualized maintenance costs, patient/caregiver time costs, absenteeism, and presenteeism costs were derived from previous studies of chronic HCV and adjusted to 2018 US dollars $[18,19,36,37]$. Patients achieving SVR were assigned lower costs for absenteeism and presenteeism, based on evidence of an HCV population compared to matched controls [37]. Patients who did not reach SVR in year 1 entered the natural progression model of liver disease, incurring annual maintenance costs associated with each stage of advanced disease. Patients reaching the transplant stage only stayed in the 'transplant' health state for 1 year, immediately progressing to the post-transplant state in the following cycle [38].

\subsection{Health Benefits}

Health-state utility estimates were found from multiple studies, including a meta-analysis of Short Form-36 scores in HCV patients that were transformed into utility weights using multiple methods $[39,40]$. These estimates were used to calculate QALYs as a model outcome in accordance with recommendations [5]. Beyond the traditional QALY health outcome, this study included two novel outcome measures developed from the HCV patient Delphi panel and reviewed by our SAB. Patients identified "fear of harming others" as an important problem caused by having $\mathrm{HCV}$ in addition to the consideration of indirect costs such as "financial issues" or "impact on work or career." This patient input was used to develop two measurable health outcomes in our model: infected life-years (ILYs) and workdays missed. In order to calculate ILYs for each hypothetical patient in the model, a tracker was developed to count the cycles the patient spent in an "infected" health state (i.e., natural history health states and advanced progression health states). The ILY tracker did not include potential years with the disease prior to entering the model. The workdays missed estimate was calculated for each cycle from absenteeism rates previously reported for $\mathrm{HCV}$ patients (5.03\% annually) compared to matched controls (2.82\% annually) multiplied by 250 days in the working calendar (5 days per week, 50 weeks per year) [37]. Patients in active $\mathrm{HCV}$ health states experienced these additional workdays missed. Since negative ILYs and workdays missed were beneficial, for consistent comparison, these outcomes were multiplied by -1 to convert the incremental comparison to a cost per outcome avoided.
Table 1 Cost components included in the reference-case perspectives recommended by the second panel [5]

\begin{tabular}{llll}
\hline Sector & Cost component & Healthcare sector & Societal \\
\hline Health & Direct medical costs & Yes & Yes \\
Informal health & Indirect costs (patient and caregiver time) & No & Yes \\
Non-health & Labor market earnings lost (absenteeism) & No & Yes \\
& Productivity loss (presenteeism) & No & Yes \\
\hline
\end{tabular}




\subsection{Analyses}

The health state model was developed using TreeAge Pro ${ }^{\circledR}$ based on the structure in Fig. 1 and a detailed Markov process outlined in supplementary Figure 2 (see the supplementary electronic material) [41]. Both US health sector and societal perspective base cases were estimated in accordance with the recommendations and based on feedback from the SAB to account for patient-informed outcomes [5]. The SAB and coauthors reviewed the model structure and results for face validity and provided input during model development [42]. Additionally, model structure, data inputs, and coding logic were presented by the lead author (TJM) and evaluated by two co-authors (JFS, EO) to improve internal validity of the calculations in TreeAge Pro ${ }^{\circledR}$. To avoid potential double counting of productivity costs (absenteeism and presenteeism) in the numerator and denominator of the societal perspective, workdays missed were only used as potential benefits in the health sector model. Inputs used for each base case were derived from published literature, and are listed in Table 2. Additional one-way sensitivity analyses were conducted based on high-low estimates and a probabilistic sensitivity analysis with 1000 repetitions. The assigned probability distributions for the model parameters are listed in Table 2 [23].

\section{Results}

\subsection{Stakeholder Advisory Board Meetings}

A total of $11 \mathrm{SAB}$ meetings were convened from 2017-2019, spanning different stages of the project, with three meetings focused on economic model development. Meeting agendas and minutes were recorded and shared with the group. The reference-case results were presented to the committee and discussed, but no formal vote was taken for a preferred outcome. The SAB members believed that multiple outcomes might be used by different audiences and that summarizing in a patient-friendly format (such as a blog post) was appropriate.

\subsection{Health Sector Perspective}

When comparing treated patients to those who did not receive DAAs, treatment resulted in greater direct costs (difference \$25,078), more QALYs (difference 0.63), fewer ILYs (difference -7.24), and fewer workdays missed (difference -35.05) in the 10-year health sector perspective. When comparing treated patients to those who did not receive DAAs, over a 20-year time horizon, treatment resulted in greater direct costs (difference \$8077), more QALYs

\section{Structural Model}

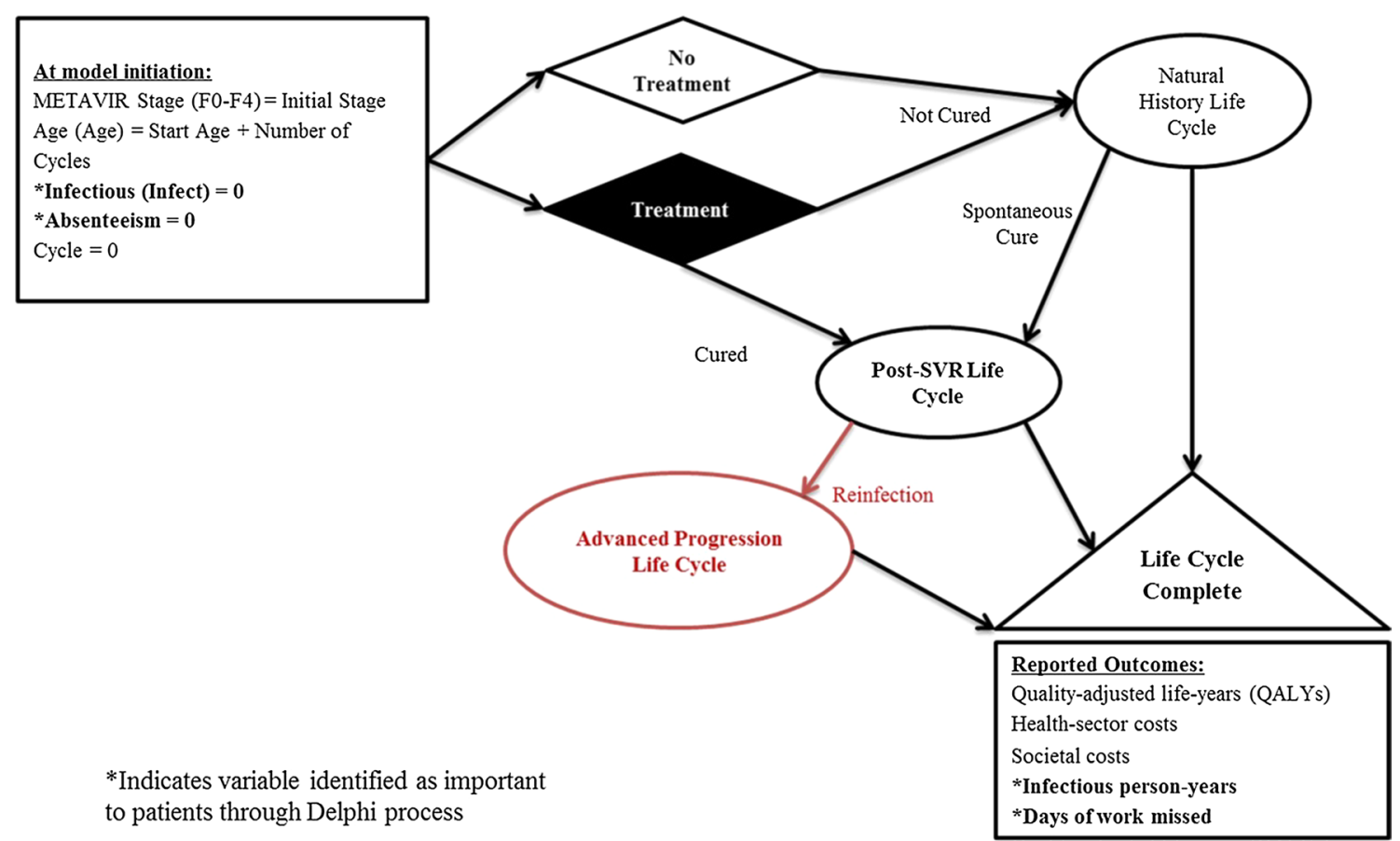

Fig. 1 General model overview with patient-centered variables. SVR sustained virologic response 
Table 2 Full list of inputs used in economic model and sensitivity analysis

\begin{tabular}{|c|c|c|c|c|c|c|c|}
\hline Input & Base case & Range & Source & Distribution & Alpha & Beta & Notes \\
\hline \multicolumn{8}{|l|}{ General } \\
\hline Age at entry & 50.0 & $40.0-60.0$ & & Normal & - & - & \\
\hline Discount rate & 0.03 & $0.00-0.05$ & & - & - & - & \\
\hline Total cycles & 10,20 & $10-20$ & & - & - & - & \\
\hline Treatment success & 0.90 & $0.82-0.98$ & {$[29,30]$} & Beta & 105.5 & 10.5 & Alpha and beta fit visually \\
\hline \multicolumn{8}{|l|}{ Transition probabilities } \\
\hline Spontaneous cure at F0 & 0.012 & $0.007-0.017$ & {$[16]$} & Beta & 8.05 & 925.5 & Alpha and beta fit visually \\
\hline F0 to F1 (age < 40) & 0.151 & $0.082-0.163$ & {$[27]$} & Beta & 10.11 & 80.5 & \\
\hline F0 to F1 (age $\geq 40)$ & 0.110 & $0.098-0.123$ & [27] & Beta & 274.98 & 2075.30 & \\
\hline F1 to F2 $($ age $<40)$ & 0.115 & $0.082-0.163$ & {$[27]$} & Beta & 10.11 & 80.5 & \\
\hline $\mathrm{F} 1$ to $\mathrm{F} 2($ age $\geq 40)$ & 0.079 & $0.069-0.090$ & {$[27]$} & Beta & 210.06 & 2261.18 & \\
\hline F2 to F3 (age < 40) & 0.142 & $0.113-0.178$ & {$[27]$} & Beta & 24.05 & 145.5 & \\
\hline $\mathrm{F} 2$ to $\mathrm{F} 3($ age $\geq 40)$ & 0.116 & $0.104-0.129$ & {$[27]$} & Beta & 288.05 & 2112.38 & \\
\hline $\mathrm{F} 3$ to $\mathrm{F} 4($ age $<40)$ & 0.129 & $0.099-0.169$ & {$[27]$} & Beta & 24.05 & 145.5 & \\
\hline $\mathrm{F} 3$ to $\mathrm{F} 4($ age $\geq 40)$ & 0.113 & $0.100-0.128$ & {$[27]$} & Beta & 270.61 & 2062.22 & \\
\hline $\mathrm{F} 3$ to $\mathrm{DC}$ & 0.012 & $0.010-0.014$ & {$[18,33]$} & Beta & 0.14 & 28.5 & \\
\hline $\mathrm{F} 3$ to $\mathrm{HC}$ & 0.011 & $0.010-0.027$ & {$[18,33]$} & Beta & 0.2 & 14.38 & \\
\hline $\mathrm{F} 4$ to $\mathrm{DC}$ & 0.039 & $0.030-0.048$ & {$[18,33]$} & Beta & 3.51 & 86.48 & \\
\hline $\mathrm{F} 4$ to $\mathrm{HC}$ & 0.024 & $0.017-0.055$ & {$[18,33]$} & Beta & 3.5 & 123.8 & \\
\hline $\mathrm{DC}$ to $\mathrm{HC}$ & 0.068 & $0.003-0.083$ & {$[19,59]$} & Beta & 73.58 & 1008.49 & \\
\hline $\mathrm{DC}$ to $\mathrm{Tx}$ & 0.023 & $0.010-0.062$ & [19] & Beta & 1.31 & 55.44 & \\
\hline $\mathrm{HC}$ to $\mathrm{Tx}$ & 0.040 & $0.000-0.140$ & [19] & Beta & 0.59 & 14.16 & \\
\hline DC to death & 0.182 & $0.065-0.190$ & {$[17,19]$} & Beta & 1626.40 & 7309.88 & \\
\hline $\mathrm{HC}$ to death & 0.427 & $0.330-0.860$ & [19] & Beta & 21.4 & 28.7 & \\
\hline Tx to death & 0.116 & $0.060-0.420$ & {$[38]$} & Beta & 1.37 & 6.88 & Alpha and beta fit visually \\
\hline Post-Tx to death & 0.044 & $0.024-0.110$ & [19] & Beta & 1.63 & 35.46 & \\
\hline \multicolumn{8}{|l|}{ Post-SVR } \\
\hline $\mathrm{F} 0$ to $\mathrm{F} 1$ & Calculated & $0.005-0.015$ & {$[18,31]$} & & & & \multirow{4}{*}{$\begin{array}{l}\text { Post-SVR progression rates from F0-F4 } \\
\text { are reduced by } 91.4 \%[18,31]\end{array}$} \\
\hline $\mathrm{F} 1$ to $\mathrm{F} 2$ & Calculated & $0.005-0.015$ & {$[18,31]$} & & & & \\
\hline $\mathrm{F} 2$ to $\mathrm{F} 3$ & Calculated & $0.005-0.015$ & {$[18,31]$} & & & & \\
\hline $\mathrm{F} 3$ to $\mathrm{F} 4$ & Calculated & $0.005-0.015$ & {$[18,31]$} & & & & \\
\hline $\mathrm{F} 3$ to $\mathrm{DC}$ & 0.00102 & $0.0005-0.015$ & {$[18,31]$} & Beta & 0.075 & 55.5 & \multirow[t]{8}{*}{ Alpha and beta fit visually } \\
\hline $\mathrm{F} 3$ to $\mathrm{HC}$ & 0.00475 & $0.001-0.007$ & {$[18,31]$} & Beta & 0.088 & 105.5 & \\
\hline $\mathrm{F} 4$ to $\mathrm{DC}$ & 0.00334 & $0.002-0.005$ & {$[18,31]$} & Beta & 0.069 & 122.5 & \\
\hline $\mathrm{F} 4$ to $\mathrm{HC}$ & 0.01245 & $0.006-0.019$ & {$[18,31]$} & Beta & 0.24 & 122.5 & \\
\hline $\mathrm{DC}$ to $\mathrm{HC}$ & 0.010 & $0.008-0.017$ & {$[18]$} & Beta & 0.35 & 122.5 & \\
\hline $\mathrm{DC}$ to $\mathrm{Tx}$ & 0.012 & $0.007-0.016$ & {$[18]$} & Beta & 0.24 & 122.5 & \\
\hline $\mathrm{HC}$ to $\mathrm{Tx}$ & 0.040 & $0.000-0.140$ & [19] & Beta & 0.59 & 14.16 & \\
\hline Reinfection & 0.005 & $0.001-0.015$ & {$[34]$} & Beta & 0.95 & 225.5 & \\
\hline Advanced progression & Calculated & & & & & & Calculated as $2 \times$ natural history \\
\hline \multicolumn{8}{|l|}{ Costs-direct } \\
\hline DAA treatment (FSS) & 38,861 & $18,023-65,722$ & {$[60]$} & Gamma & 9 & 0.0002317 & Alpha and beta fit visually \\
\hline $\mathrm{F} 0$ to $\mathrm{F} 2$ & 912 & $456-3647$ & {$[18,19]$} & Gamma & 4 & 0.00439 & \\
\hline F3 & 2419 & $1210-9679$ & {$[18,19]$} & Gamma & 2 & 0.000827 & \\
\hline F4 & 2832 & $1416-11,327$ & {$[18,19]$} & Gamma & 2 & 0.0007 & \\
\hline DC & 33,535 & $31,471-35,596$ & {$[18,19]$} & Gamma & 60 & 0.00177 & \\
\hline $\mathrm{HC}$ & 53,490 & $52,508-58,968$ & {$[18,19]$} & Gamma & 60 & 0.0011 & \\
\hline $\mathrm{Tx}$ & 212,351 & $195,823-228,873$ & {$[18,19]$} & Gamma & 200 & 0.00094 & \\
\hline PTx & 46,247 & $37,790-54,706$ & {$[18,19]$} & Gamma & 60 & 0.00128 & \\
\hline
\end{tabular}


Table 2 (continued)

\begin{tabular}{|c|c|c|c|c|c|c|c|}
\hline Input & Base case & Range & Source & Distribution & Alpha & Beta & Notes \\
\hline Post-SVR F0-F4 & Calculated & - & [18] & - & - & - & $\begin{array}{l}\text { Post-SVR costs in F0-F4 are reduced } \\
\text { by } 50 \%[18]\end{array}$ \\
\hline \multicolumn{8}{|l|}{ Costs_indirect } \\
\hline Time (F0-F3) & 5493 & $3075-7911$ & {$[36]$} & Gamma & 43.5 & 0.008 & \multirow[t]{10}{*}{ Alpha and beta fit visually } \\
\hline Time (F4-DC) & 8357 & $5939-10,875$ & {$[36]$} & Gamma & 58.5 & 0.007 & \\
\hline Time (HC) & 7561 & 5143-9979 & {$[36]$} & Gamma & 150.5 & 0.02 & \\
\hline Time (Tx-PTx) & 15,904 & $13,486-18,322$ & [36] & Gamma & 238.5 & 0.015 & \\
\hline Time (SVR) & 4565 & $2147-6983$ & {$[36]$} & Gamma & 36.5 & 0.008 & \\
\hline Absenteeism (SVR) & 1323 & $0-1654$ & [37] & Gamma & 1.11 & 0.00084 & \\
\hline Absenteeism (HCV) & 2107 & $0-2634$ & [37] & Gamma & 1.77 & 0.00084 & \\
\hline Presenteeism (SVR) & 5604 & $0-7005$ & [37] & Gamma & 1.14 & 0.0002 & \\
\hline Presenteeism (HCV) & 10,399 & $0-12,999$ & [37] & Gamma & 1.14 & 0.00011 & \\
\hline Absent rate & 0.0221 & $0.0032-0.0442$ & [37] & Beta & 1.85 & 105 & \\
\hline \multicolumn{8}{|l|}{ Health state utilities } \\
\hline $\mathrm{F} 0-\mathrm{F} 1$ & 0.98 & $0.7-1.0$ & {$[39,40]$} & Beta & 40.5 & 4.5 & \multirow[t]{11}{*}{ Alpha and beta fit visually } \\
\hline $\mathrm{F} 2-\mathrm{F} 3$ & 0.85 & $0.66-1.0$ & {$[39,40]$} & Beta & 26.5 & 5.5 & \\
\hline $\mathrm{F} 4$ & 0.79 & $0.46-1.0$ & {$[39,40]$} & Beta & 11.55 & 3.05 & \\
\hline DC & 0.72 & $0.26-0.91$ & {$[39,40]$} & Beta & 10.55 & 4.5 & \\
\hline $\mathrm{HC}$ & 0.72 & $0.15-0.95$ & {$[39,40]$} & Beta & 9.5 & 3.3 & \\
\hline $\mathrm{Tx}$ & 0.5 & $0.45-0.69$ & {$[18,40]$} & Beta & 31.85 & 29.45 & \\
\hline PTx & 0.83 & $0.64-0.93$ & {$[39,40]$} & Beta & 12.25 & 3.05 & \\
\hline Post-SVR F0-F1 & 1.0 & $0.74-1.0$ & {$[39,40]$} & Beta & 75 & 4.5 & \\
\hline Post-SVR F2-F3 & 0.93 & $0.71-1.0$ & {$[39,40]$} & Beta & 55 & 4.5 & \\
\hline Post-SVR F4 & 0.79 & $0.46-1.0$ & {$[39,40]$} & Beta & 11.55 & 3.05 & \\
\hline Dead & 0 & - & & - & & & \\
\hline
\end{tabular}

$D A A$ direct-acting antiviral, $D C$ decompensated cirrhosis, FSS Federal Supply Schedule, $H C$ hepatocellular carcinoma, $H C V$ hepatitis $C$ virus, $P T x$ post-transplant, $S V R$ sustained virologic response, $T x$ transplant

(difference 1.66), fewer ILYs (difference - 13.11), and fewer workdays missed (difference - 63.85). The potential ICERs over a 20-year time horizon for treatment were \$4866/QALY gained, \$616/ILY, and \$126/workdays missed (Table 3).

\subsection{Societal Perspective}

From a societal perspective, 10- and 20-year scenarios demonstrated that treating patients with DAAs reduced total costs by $\$ 18,921$ and $\$ 54,261$, respectively (Table 3). Treatment dominated the 'no treatment' arm at any willingnessto-pay (WTP) threshold because it produced greater health outcomes (QALY and ILY) at a lower cost.

\subsection{Sensitivity Analysis}

Overall, the sensitivity analyses demonstrated the importance of specific variable inputs in each perspective. While certain inputs created wider variation than others (median drug costs, utility estimates in healthier states, costs of presenteeism and absenteeism in the societal perspective, etc.), the models were robust at a $\$ 100,000 / \mathrm{QALY}$ WTP threshold.

Results of the parameter adjustments are presented in tornado diagrams for health sector and societal models for 10and 20-year time horizons (supplementary Figures 2-5; see the electronic supplementary material). The results of the second-order probabilistic sensitivity analysis are presented using scatter plots of cost-effect pairs and cost-effectiveness acceptability curves (CEAC) with increasing WTP in supplementary Figures 6-13 (see the electronic supplementary material).

\section{Discussion}

While the US has no explicit WTP threshold for cost effectiveness, the use of DAAs in our model resulted in better outcomes at a cost below historic thresholds used for this type of analysis (e.g., \$50,000-\$150,000/QALY) [43-45]. When considering societal perspective costs, including patient/caregiver time and productivity losses through 
Table 3 Reference-case cost-effectiveness results

\begin{tabular}{|c|c|c|c|c|}
\hline$N=10,000$ & No treatment $[95 \% \mathrm{CI}]$ & Treatment $[95 \% \mathrm{CI}]$ & Difference $^{a}$ & Incremental cost-effectiveness ratios \\
\hline \multicolumn{5}{|l|}{ 10-year model } \\
\hline \multicolumn{5}{|l|}{ Cost } \\
\hline Health sector & $24,096[4617-148,601]$ & $49,174[41,786-93,445]$ & 25,078 & $\begin{array}{l}\text { \$39,806/QALY } \\
\text { \$3464/ILY avoided } \\
\text { \$715/workdays missed avoided }\end{array}$ \\
\hline Societal & $173,780[62,946-301,160]$ & $154,859[92,724-235,354]$ & $-18,921$ & Treatment dominant $^{\mathrm{c}}$ \\
\hline \multicolumn{5}{|l|}{ Effectiveness } \\
\hline QALYs & $7.27[2.43-8.48]$ & $7.90[3.89-8.65]$ & 0.63 & \\
\hline ILYs & $9.30[3.00-10.00]$ & $2.06[1.00-10.00]$ & -7.24 & \\
\hline Workdays missed & $51.37[16.58-55.25]$ & $16.32[5.53-55.25]$ & -35.05 & \\
\hline \multicolumn{5}{|l|}{ 20-year model } \\
\hline \multicolumn{5}{|l|}{ Cost } \\
\hline Health sector & $51,704[4631-272,420]$ & $59,781[42,157-172,612]$ & 8077 & $\begin{array}{l}\text { \$4866/QALY gained } \\
\text { \$616/ILY avoided } \\
\text { \$126/workdays missed avoided }\end{array}$ \\
\hline Societal & $287,306[62,946-530,579]$ & $233,045[95,527-388,007]$ & $-54,261$ & Treatment dominant $^{\mathrm{c}}$ \\
\hline \multicolumn{5}{|l|}{ Effectiveness } \\
\hline QALYs & $11.35[2.46-14.80]$ & $13.01[3.98-15.09]$ & 1.66 & \\
\hline ILYs & $16.44[3.00-20.00]$ & $3.33[1.00-20.00]$ & -13.11 & \\
\hline Workdays missed & $90.85[16.58-110.5]$ & $27.00[5.53-110.50]$ & -63.85 & \\
\hline
\end{tabular}

$C I$ confidence interval, $I L Y$ infected life-year, $Q A L Y$ quality-adjusted life-year

${ }^{a}$ Mean values for [treatment - no treatment]

$\mathrm{b}$ [Treatment - no treatment $] \times-1$ to convert to cost per outcome avoidance

${ }^{\mathrm{c}}$ Treatment dominant refers to the treatment group being less costly and more effective than the no treatment group

patient absenteeism and presenteeism, DAAs were costsaving in both 10- and 20-year scenarios. Treatment also leads to a reduction in number of years living with the virus and the number of workdays missed. Our 20-year health sector ICER of \$4866/QALY outcome was generally more favorable than the ICERs calculated with comparable models, but many models report recommendations that result in the same decision to treat [18, 46-48].

To our knowledge, this is the first patient-centered economic model developed for HCV treatments utilizing a patient-centered SAB along with a patient Delphi to guide research decisions and methods chosen. Since the advent of DAAs, traditional economic models using a cost/QALY endpoint have demonstrated the cost effectiveness of these therapies using a variety of methods, populations, perspectives, treatments, and comparators [8, 49]. Despite all of the research variations, economic modelers have not incorporated patients as stakeholders in the model-development process, potentially limiting its use as CER as defined by the Institute of Medicine [50]. Furthermore, by using a systematic approach for continuous patient engagement, we were able to capture a perspective of "value" for treatment decision-making that was different to what has been identified previously by clinicians, researchers, and payers $[12,13]$.
The use of the QALY as a primary health outcome measure in economic models has been a standard of practice since the first Panel on Cost-Effectiveness in Health and Medicine convened in the early 1990s [4]. Health economists agree that this measure's advantages outweigh some of its limitations, and leading experts continue to recommend a cost/ QALY outcome as the "starting point" to inform value decisions [51]. This recommendation does not preclude investigators from exploring new ways to analyze and disseminate the results of CEA. In fact, there is a great deal of discussion regarding alternatives to this single endpoint approach [52-54]. We argue, thanks to suggestions from individuals with lived experience with HCV, CEAs for interventions in HCV should go beyond this starting point by including multiple denominators for comparison. We propose two new denominators that are meant to enhance the value assessment discussion for this clinical scenario.

In the US, the predominance of employer-sponsored health plans adds nuance to the discussion around value and the determination of a WTP threshold [55]. Economic models that only report a QALY-based outcome may not fully resonate with an employer's senior leadership team while making health plan decisions. The results of the patient-centered CEA reported workdays missed in the treatment and no treatment groups in addition to conducting the analysis 
from a societal perspective that captured productivity cost estimates. Comparing the incremental costs of treatment with the number of workdays a cured patient can potentially gain back may provide greater clarity, as compared to interpreting cost/QALY, around the opportunity costs involved that would directly impact the employer. These results were understood by the SAB, but whether or not formulary decision-makers within payer organizations would find this information useful was not addressed. A meaningful next step would be to convene experts within managed care organizations and solicit feedback on the model results. Patient engagement within health technology assessment conducted in countries with single government payer systems also benefit by capturing more components of value defined by the patient population coverage determinations' impact.

The ILY outcome was a result of conducting this research within an infectious disease area, but is likely not of interest for diseases that are not communicable. Continuous patient engagement requires talking with patients early and often throughout the research process [12]. This suggests that starting with a blank slate is not only encouraged, but necessary to reduce investigator-initiated bias. Systematically capturing patient input through advisory boards, focus groups, and semi-structured interviews can be costly and time-consuming, but these steps are paramount to patient-centered CEA development. However, which engagement method is most appropriate to guide health economists is unknown. Researching patient engagement with different types of patients informing different CEA approaches (observational studies, models, etc.) may help identify best practices moving forward.

Beyond cost effectiveness, other organizations are considering systematically including patient perspectives throughout guidelines and other processes. For example, the Food and Drug Administration has begun using the term "patient-focused drug development" to describe new initiatives to engage patients and patient advocacy organizations to capture patient perspectives on disease severity or potential unmet needs in a disease area that may benefit the drug review process [56]. These initiatives may provide a new reference for regulatory decisions, but additional research may be warranted to evaluate potential unintended consequences of a shift towards patient-centeredness [57].

Our study has several limitations that should be considered when interpreting the results. First, both the initial medication treatment cost and effectiveness inputs for a patient entering the model were simplified to reflect an average patient case. This was determined in consultation with our $\mathrm{SAB}$, which was less concerned with the specific treatment regimen because of the availability of multiple once-a-day DAAs with similar rates of SVR. Notable comments from the SAB include statements such as, "Patients do not use terms like 'quality-of-life' but they may infer it" and "patients should be treated holistically." While we incorporated different adjustments and assumptions through sensitivity analyses, special populations (such as incarcerated patients) which constitute a non-negligible proportion of HCV patients may need to be considered separately. Our supplemental file aims to provide complete transparency to allow other researchers to replicate our model and make any necessary input adjustments to test if this approach would yield similar results in unique populations.

Additionally, data on time and productivity costs for $\mathrm{HCV}$ patients were sparse compared to the data available for direct health costs that are frequently used in CEAs for these drugs. We used published estimates for time and productivity (absenteeism and presenteeism) costs from a study of 306 HCV patients compared with propensity matched controls using the Work Productivity and Activity Impairment questionnaire [36, 37]. This self-reported time and productivity loss may overestimate actual productivity losses [58]. The patient and caregiver time costs were combined to be consistent with the way in which the original study collected this information and the way results were reported in their final regression model [36]. The time costs estimates used in our analysis were from a study of $738 \mathrm{HCV}$ outpatients in Canada, potentially limiting the generalizability to time costs in the US despite our conversion and inflation adjustments. Additionally, absenteeism and presenteeism estimates were based on a US survey that may not be completely representative of marginalized populations or the incarcerated population. In our one-way sensitivity analyses, we used zero as the lower limit for all of these estimates and found that the 10- and 20-year models were sensitive to the inputs for presenteeism in the HCV and non-HCV groups. Our model was not sensitive to age at model initiation, but more detailed scenario analyses for different age cohorts may be important when considering many societal perspective items or potential spillover effects on caregivers.

Given the approach of utilizing a patient-centered SAB along with a patient Delphi to guide research decisions has not been widely implemented in economic modeling, we have little evidence to compare whether our advisor recommendations would have differed greatly with a larger board or completely different set of advisors. Patients selected for the SAB and Delphi were considered experts based on their lived experience, and their input was treated the same as any other clinical or methodological input offered by other advisors.

\section{Conclusions}

In terms of cost-effectiveness, treatment of $\mathrm{HCV}$ with highly effective DAAs improves disease burden and outcomes identified by patients. Using a patient-centered approach, additional costs and outcomes meaningful to $\mathrm{HCV}$ patients were 
identified and then implemented, specifically cost/ILY and cost/workdays missed ICER estimates. Treatment was cost effective from a health sector perspective and cost-saving when including non-health costs such as patient/caregiver time and productivity.

Acknowledgements The authors would like to thank the study advisory board members for their contribution to the concept, design, and interpretation of this study.

Author contributions Study concept and design: all authors. Drafting of manuscript: TJM. Critical reviews: all authors. Statistical analysis: TJM. Interpretation of data: all authors. Final version approval: all authors.

\section{Compliance with Ethical Standards}

Grant support The Stakeholder Advisory Board described in this manuscript was initiated with a research grant from the Patient-Centered Outcomes Research Institute (7709720-A).

Data availability statement All input data for the decision analytical model are available within the article and the electronic supplementary material. The decision analytical model is available from the corresponding author on reasonable request.

Conflict of interest TJM reports consultant fees from G\&W Labs, BMS, PhRMA, and NHC, all unrelated to this research. EO reports grants from Bayer Healthcare Pharmaceuticals, Inc. and from Pfizer, personal fees from Novo Nordisk, unrelated to this work. EMP is an employee of the National Health Council, which receives membership dues and sponsorship funding from a wide range of organizations. For the full list, please see http://www.nhcouncil.org. JFS reports grants from Novartis Pharmaceuticals, Takeda Pharmaceuticals, the PhRMA Foundation, and PhRMA unrelated to this work, as well as teaching honorarium from Pfizer. SK reports grants from Gilead Sciences, Merck, and Arbutus Pharma. CDM reports grants from Merck and consulting fees from Bayer, Boehringer-Ingelheim, Illumina, Janssen, Merck, Pfizer, Regeneron, and Sanofi.

Open Access This article is distributed under the terms of the Creative Commons Attribution-NonCommercial 4.0 International License (http://creativecommons.org/licenses/by-nc/4.0/), which permits any noncommercial use, distribution, and reproduction in any medium, provided you give appropriate credit to the original author(s) and the source, provide a link to the Creative Commons license, and indicate if changes were made.

\section{References}

1. Forsythe L, Heckert A, Margolis MK, Schrandt S, Frank L. Methods and impact of engagement in research, from theory to practice and back again: early findings from the Patient-Centered Outcomes Research Institute. Qual Life Res. 2018;27:17-31.

2. Patient-Centered Outcomes Research Institute. Fiscal year 2017 annual report (Internet). Washington, D.C.; 2018. https://www. pcori.org/sites/default/files/PCORI-Annual-Report-2017.pdf.

3. Patient Protection and Affordable Care Act. 42 U.S.C. $§ 18001$ 2010.
4. Weinstein MC, Siegel JE, Gold MR, Kamlet MS, Russell LB. Recommendations of the panel on cost-effectiveness in health and medicine. JAMA (J Am Med Assoc). 1996;276:1253-8.

5. Sanders GD, Neumann PJ, Basu A, Brock DW, Feeny D, Krahn $\mathrm{M}$, et al. Recommendations for conduct, methodological practices, and reporting of cost-effectiveness analyses. JAMA. 2016;316:1093-103.

6. Neumann PJ, Weinstein MC. Legislating against use of cost-effectiveness information. N Engl J Med. 2010;363:1495-7.

7. Smith-Palmer J, Cerri K, Valentine W. Achieving sustained virologic response in hepatitis C: a systematic review of the clinical, economic and quality of life benefits. BMC Infect Dis BioMed Central. 2015;15:332-65.

8. Chhatwal J, He T, Lopez-Olivo MA. Systematic review of modelling approaches for the cost effectiveness of hepatitis $\mathrm{C}$ treatment with direct-acting antivirals. Pharmacoeconomics (Springer International Publishing). 2016;34:551-67.

9. Tice JA, Ollendorf DA, Chahal HS, Kahn JG, Marseille E, Weissberg J, et al. The comparative clinical effectiveness and value of novel combination therapies for the treatment of patients with genotype 1 chronic hepatitis $\mathrm{C}$ infection: a technology assessment. Institute for Clinical and Economic Review. 2015. Available at: https://icer-review.org/wp-content/uploads/2016/01/ CTAF_HCV2_Final_Report_013015.pdf.

10. Institute for Quality and Efficiency in Health Care. Institute for Quality and Efficiency in Health Care (IQWiG): IQWiG methods resources. Choice-based conjoint analysis-pilot project to identify, weight, and prioritize multiple attributes in the indication "hepatitis C". 2014.

11. Mühlbacher AC, Sadler A, Muhlbacher AC, Sadler A, Mühlbacher AC, Sadler A. The probabilistic efficiency frontier: a framework for cost-effectiveness analysis in Germany put into practice for hepatitis C treatment options. Value Health. 2017;20:266-72.

12. Mullins CD, Abdulhalim AM, Lavallee DC. Continuous patient engagement in comparative effectiveness research. JAMA. 2012;307:1587-8.

13. Perfetto EM, Oehrlein EM, Boutin M, Reid S, Gascho E. Value to whom? The patient voice in the value discussion. Value Health. 2017;20:286-91.

14. Mattingly TJ II, Perfetto EM, Johnson SL. Engaging hepatitis C infected patients in cost-effectiveness analyses: a literature review. Hepatology. 2018;23:774-81.

15. Mattingly II TJ, Slejko JF, Perfetto EM, Kottilil S, Mullins CD. What matters most for treatment decisions in hepatitis C: effectiveness, costs, and altruism patient (Internet). 2019; in print 1-8. https://doi.org/10.1007/s40271-019-00378-7.

16. Liu S, Cipriano LE, Holodniy M, Owens DK, Goldhaber-Fiebert JD. New protease inhibitors for the treatment of chronic hepatitis C: a cost-effectiveness analysis. Ann Intern Med. 2012;156:279-90.

17. Najafzadeh M, Andersson K, Shrank WH, Krumme AA, Matlin OS, Brennan T, et al. Cost-effectiveness of novel regimens for the treatment of hepatitis C virus. Ann Intern Med. 2015;162:407-19.

18. Chahal HS, Marseille EA, Tice JA, Pearson SD, Ollendorf DA, Fox RK, et al. Cost-effectiveness of early treatment of hepatitis $C$ virus genotype 1 by stage of liver fibrosis in a US treatment-naive population. JAMA Intern Med. 2016;176:65-73.

19. Chhatwal J, Kanwal F, Roberts MSMS, Dunn MAMA. Costeffectiveness and budget impact of hepatitis $C$ virus treatment with sofosbuvir and ledipasvir in the United States. Ann Intern Med. 2015;162:397-406.

20. Manos MM, Shvachko VA, Murphy RC, Arduino JM, Shire NJ. Distribution of hepatitis C virus genotypes in a diverse US integrated health care population. J Med Virol. 2012;84:1744-50.

21. Denniston MM, Jiles RB, Drobeniuc J, Klevens RM, Ward JW, McQuillan GM, et al. Chronic hepatitis $\mathrm{C}$ virus infection in the 
United States, National Health and Nutrition Examination Survey 2003 to 2010. Ann Intern Med. 2014;160:293-300.

22. Centers for Disease Control \& Prevention. Surveillance for viral hepatitis-United States, 2016 (Internet). 2016. https://www.cdc. gov/hepatitis/statistics/2016surveillance/index.htm.

23. Caro JJ, Briggs AH, Siebert U, Kuntz KM, ISPOR-SMDM Modeling Good Research Practices Task Force. Modeling good research practices-overview: a report of the ISPOR-SMDM Modeling Good Research Practices Task Force-1. Med Decis Mak. 2012;15:796-803.

24. AASLD/ISDA. HCV guidance: recommendations for testing, managing, and treating hepatitis C. 2019 (Internet). http://www. hcvguidelines.org/full-report-view. Accessed 18 Mar 2019.

25. Bedossa P, Poynard T. An algorithm for the grading of activity in chronic hepatitis C. The METAVIR Cooperative Study Group. Hepatology. 1996;24:289-93.

26. Chhatwal J, He T, Hur C, Lopez-Olivo MA. Direct-acting antiviral agents for patients with hepatitis $\mathrm{C}$ virus genotype 1 infection are cost-saving. Clin Gastroenterol Hepatol. 2017;15:827-37.

27. Thein HH, Yi Q, Dore GJ, Krahn MD. Estimation of stage-specific fibrosis progression rates in chronic hepatitis $\mathrm{C}$ virus infection: a meta-analysis and meta-regression. Hepatology. 2008;48:418-31.

28. Poynard T, Bedossa P, Opolon P. Natural history of liver fibrosis progression in patients with chronic hepatitis C. Lancet. 1997;349:825-32.

29. Hajarizadeh B, Cunningham EB, Reid H, Law M, Dore GJ, Grebely J. Direct-acting antiviral treatment for hepatitis $\mathrm{C}$ among people who use or inject drugs: a systematic review and metaanalysis. Lancet Gastroenterol Hepatol. 2018;3:754-67.

30. Sikavi C, Chen PH, Lee AD, Saab EG, Choi G, Saab S. Hepatitis $\mathrm{C}$ and human immunodeficiency virus coinfection in the era of direct-acting antiviral agents: no longer a difficult-to-treat population. Hepatology. 2018;67:847-57.

31. Pearlman BL, Traub N. Sustained virologic response to antiviral therapy for chronic hepatitis $\mathrm{C}$ virus infection: a cure and so much more. Clin Infect Dis. 2011;52:889-900.

32. Ghany MG, Strader DB, Thomas DL, Seeff LB. Diagnosis, management, and treatment of hepatitis C: an update. Hepatology. 2009;49:1335-74

33. Dienstag JL, Ghany MG, Morgan TR, Di Bisceglie AM, Bonkovsky HL, Kim H-Y, et al. A prospective study of the rate of progression in compensated, histologically advanced chronic hepatitis C. Hepatology. 2011;54:396-405.

34. Liu S, Watcha D, Holodniy M, Goldhaber-Fiebert JDJD. Sofosbuvir-based treatment regimens for chronic, genotype 1 hepatitis $\mathrm{C}$ virus infection in U.S. incarcerated populations: a cost-effectiveness analysis. Ann. Intern. Med. 2014;161:546-53.

35. Levy J, Rosenberg M, Vanness D. A Transparent and consistent approach to assess US outpatient drug costs for use in cost-effectiveness analyses. Value Health. 2018;21:677-84.

36. Federico CA, Hsu PC, Krajden M, Yoshida EM, Bremner KE, Weiss AA, et al. Patient time costs and out-of-pocket costs in hepatitis C. Liver Int. 2012;32:815-25.

37. El Khoury AC, Vietri J, Prajapati G. The burden of untreated hepatitis c virus infection: a US patients' perspective. Dig. Dis. Sci. 2012;57:2995-3003

38. Wolfe RA, Roys EC, Merion RM. Trends in organ donation and transplantation in the United States, 1999-2008: special feature. Am J Transplant. 2010;10:961-72.

39. Chong CAKY, Gulamhussein A, Jenny Heathcote E, Lilly L, Sherman M, Naglie G, et al. Health-state utilities and quality of life in hepatitis C patients. Am J Gastroenterol. 2003;98:630-8.

40. Thein HH, Krahn M, Kaldor JM, Dore GJ. Estimation of utilities for chronic hepatitis C from SF-36 scores. Am J Gastroenterol. 2005;100:643-51.
41. TreeAge Pro (Internet). Williamstown: TreeAge software; 2016. https://www.treeage.com.

42. Eddy DM, Hollingworth W, Caro JJ, Tsevat J, McDonald KM, Wong JB. Model transparency and validation: a report of the ISPOR-SMDM Modeling Good Research Practices Task Force7. Med Decis Mak. 2012;32:733-43.

43. Hirth RA, Chernew ME, Miller E, Fendrick AM, Weissert WG. Willingness to pay for a quality-adjusted life year: in search of a standard (review) (70 refs). Med Decis Mak. 2000;20:332-42.

44. Bridges JFP, Onukwugha E, Mullins CD. Healthcare rationing by proxy: cost-effectiveness analysis and the misuse of the $\$ 50000$ threshold in the US. Pharmacoeconomics. 2010;28:175-84.

45. Neumann PJ, Cohen JT. QALYs in 2018-advantages and concerns. JAMA. 2018;319:2473-4.

46. Saab S, Gordon SC, Park H, Sulkowski M, Ahmed A, Younossi Z. Cost-effectiveness analysis of sofosbuvir plus peginterferon/ ribavirin in the treatment of chronic hepatitis $\mathrm{C}$ virus genotype 1 infection. Aliment Pharmacol Ther. 2014;40:657-75.

47. Saab S, Parisé H, Virabhak S, Wang A, Marx SE, Sanchez Gonzalez Y, et al. Cost-effectiveness of currently recommended directacting antiviral treatments in patients infected with genotypes 1 or 4 hepatitis C virus in the US. J Med Econ (Internet). 2016;19:795805. http://www.ncbi.nlm.nih.gov/pubmed/27063573.

48. Liu S, Barnett PG, Holodniy M, Lo J, Joyce VR, Gidwani R, et al. Cost-effectiveness of treatments for genotype 1 hepatitis $\mathrm{C}$ virus infection in non-VA and VA populations. MDM Policy Pract. 2016;1:1-12.

49. Mattingly TJ II, Slejko JF, Mullins CD. Hepatitis C treatment regimens are cost-effective: but compared with what? Ann Pharmacother. 2017;51:961-9.

50. Sox HC. Defining comparative effectiveness research. Med Care. 2010;48:S7-8.

51. Garrison LP, Neumann PJ, Willke RJ, Basu A, Danzon PM, Doshi JA, et al. A health economics approach to US value assessment frameworks-summary and recommendations of the ISPOR Special Task Force Report [7]. Value Health. 2018;21:161-5.

52. Phelps C, Madhavan G. Resource allocation in decision support frameworks. Cost Eff Resour Alloc. 2018;16:48.

53. Mühlbacher AC. Patient-centric HTA: different strokes for different folks. Expert Rev Pharmacoecon Outcomes Res. 2015;15:591-7.

54. Nord E. Beyond QALYs: Multi-criteria based estimation of maximum willingness to pay for health technologies. Eur J Health Econ. 2018;19:267-75.

55. Danzon PM, Drummond MF, Towse A, Pauly MV. Objectives, budgets, thresholds, and opportunity costs-a health economics approach: an ISPOR Special Task Force Report [4]. Value Health (Elsevier Inc.). 2018;21:140-5.

56. Perfetto EM, Burke L, Oehrlein EM, Epstein RS. Patient-focused drug development: a new direction for collaboration. Med Care. 2015;53:9-17.

57. Mattingly TJ II, Simoni-Wastila L. Patient-centered drug approval: the role of patient advocacy in the drug approval process. J Manag Care Spec Pharm (Internet). 2017;23:1078-82. https://www.scopus.com/inward/record.uri?eid=2-s2.0-85029 $837449 \&$ doi $=10.18553 \% 2 F j m c p .2017 .23 .10 .1078 \&$ partn erID=40\&md5=ca047d9d6a7c8ebbbba233710aefc360.

58. Lerner D, Amick BC, Lee JC, Rooney T, Rogers WH, Chang H, et al. Relationship of employee-reported work limitations to work productivity. Med Care. 2003;41:649-59.

59. Planas R, Ballesté B, Álvarez MA, Rivera M, Montoliu S, Galeras JA, et al. Natural history of decompensated hepatitis $\mathrm{C}$ virus-related cirrhosis. A study of 200 patients. J. Hepatol. 2004;40:823-30.

60. U.S. Department of Veterans Affairs. VA Federal Supply Schedule Service (Internet). https://www.fss.va.gov/. Accessed 5 Feb 2019. 